http://www.jumdc.com/

Original Article

\title{
Frequency of osteoporosis in patients with peptic ulcer disease
}

\author{
Amber Amina, Qaisar Farooq $^{\text {b }}$, Rizwan Jameel ${ }^{\mathrm{c}}$ \\ ${ }^{a}$ Medical officer, Department of Medicine, Shaikh Zayed Hospital Lahore. \\ bPost-Graduate Resident, Department of Medicine, Shaikh Zayed Hospital Lahore. \\ 'Senior Registrar, Department of Medicine, Shaikh Zayed Hospital Lahore. \\ ${ }^{*}$ Corresponding author: amberamin1@gmail.com
}

\begin{abstract}
BACKGROUND \& OBJECTIVE: Peptic ulcer disease (PUD) is one of the common presentations in the medical as well as Gastroenterology clinics and it can end up in various short- and long-term complications among which osteoporosis is highly under rated. Therefore, the present study was designed to determine the frequency of osteoporosis in cases having PUD.

METHODOLOGY: A cross-sectional study was conducted at the Department of Medicine during 1st January 2020 to 30 th June 2020 in Sheikh Zayed Hospital, Lahore. The diagnosed cases of PUD on the basis of history and endoscopic findings with the age range of 20 to 60 years were included. Osteoporosis was labelled as yes, where a T-score of $\leq-2.5$ on DEXA scan was noted.

RESULTS: In this study, there were a total of 139 cases, out of which 75 (53.95\%) were males and 64 (46.05\%) females. The mean age of the participants was $48.11 \pm 9.43$ years. Osteoporosis was observed in $14(10.07 \%)$ out of 139 cases. Osteoporosis was seen in $05(6.67 \%)$ males vs $09(14.06 \%)$ females in their respective groups with $\mathrm{p}=0.148$. Osteoporosis was observed in $4(5.80 \%)$ cases with a duration of PUD up to 2 years and $10(14.28 \%)$ cases with duration more than this with $p=0.096$ CONCLUSION: Osteoporosis is not uncommon in cases with Peptic ulcer disease, and there is no significant association with any of the confounders of this study.

KEYWORDS: Dual energy X ray absorptiometry, Osteoporosis, Peptic Ulcer Disease.
\end{abstract}

\section{INTRODUCTION}

Peptic ulcer disease (PUD) is defined as an ulcerative lesion involving the stomach, first part of the duodenum, and lower part of the oesophagus It is one of the salient causes seeking medical attention in outdoor and emergency clinics. Its prevalence is higher in developing countries, due to poor dietary habits and the presence of $\mathrm{H}$ - pylori infection. Its prevalence in Pakistan is around 9.9 million cases $^{[1-2]}$.

The underlying mechanism of PUD is an imbalance between acid production and protective layers of the body in the mucosal linings. Infections also play a pivot role in this, and amongst them, Helicobacter pylori infection has shown a high association with PUD. There is a number of risk factors associated with different degrees of association, ranging from $\mathrm{H}$ pylori infections to smoking and various dietary associations ${ }^{[3-4]}$.

Osteoporosis is a relatively newer entity that has been seen in these cases and can be described as decreased bone mineralization. Bony pains, movement limitations, and easy fracture are the salient features and lead to a question for aetiology in the absence of other causes ${ }^{[5]}$.
The risk factors for osteoporosis include female gender, DM, smoking and decreased intake of calcium, etc. There are plenty of well and poorly associated factors associated with osteoporosis which can be either modifiable or nonmodifiable ${ }^{[6-8]}$. Prevalence has been variable, but a recent Pakistani study found this to be $10 \%$ in their study ${ }^{[9]}$. There is always a need for the detection of reversible factors, which can be a peptic ulcer disease. That's why this study was planned to quantify the burden of osteoporosis in cases of peptic ulcer disease.

\section{METHODOLOGY}

This was a cross-sectional study which was conducted at Department of Medicine during 1st January 2020 to 30th June 2020 of Sheikh Zayed Hospital, Lahore. The approval was taken from the ethical review committee with reference number SZH/MED/22/2020. The sample size was calculated as 139 by keeping the confidence interval equal to $95 \%$, margin of error equal to $5 \%$, and the prevalence of osteoporosis in cases of PUD as $10 \%$ in previous studies ${ }^{[9]}$. Total 178 patients were seen, and 39 were dropped due to refusal for DEXA scan. 
Informed consent was taken from all these cases explaining the details of the research and associated investigations required. Then, the subjects were included in the age range of 20 to 60 years of both genders and having PUD, which was diagnosed on the basis of history having nausea, retrosternal burning, abdominal pain, and then endoscopic finding showing ulcerative lesion of any size or depth from lower part of oesophagus to first part of the duodenum. Cases with a history of such symptom or diagnosis for at least 1 year or more on or off treatment were included.

The cases with vitamin $\mathrm{D}$ deficiency (assessed on the basis of medical record with value less than 20 IU), having any malignancy, end organ failure like liver cirrhosis and end stage renal disease (ESRD), alcoholics and any other hormonal disorder (hypo-parathyroidism) were excluded from this study. All of these subjects were then assessed for bone mineral density on the basis of dual energy $\mathrm{x}$ ray absorptiometry scan (DEXA scan). Osteoporosis was labelled as yes, where T-score of $\leq-2.5$ on DEXA scan was noted. The data were collected and recorded for further analysis, and those having osteoporosis were managed according to their clinical condition.

Detailed sociodemographic and clinical information was collected and SPSS version 23.0 was used for data entry and analysis. Data was collected by post-graduate residents and stratified against the confounders i.e. age, gender, and duration of disease. Post stratification chi-square test was applied, and a p-value of equal or less than 0.05 was taken as significant.

\section{RESULTS}

In this study, there were 139 cases out of which 75 (53.95\%) were males and $64(46.05 \%)$ females. The mean age of the participants was $48.11 \pm 9.43$ years, and the mean duration of disease was $2.1 \pm 0.27$ years, as shown in table-I. Mean T score of all subjects was $-2.7 \pm 0.9$ as in table I. Osteoporosis was observed in $14(10.07 \%)$ out of 139 cases, as displayed in figure-I.

Osteoporosis was seen in 05 (6.67\%) males vs 09 (14.06\%) females in their respective groups with $p=0.148$. There was no significant difference in terms of age groups with $\mathrm{p}=0.842$ Osteoporosis was observed in $4(5.80 \%)$ cases with duration of symptoms up to 2 years and 10 (14.28\%) cases with duration more than this with $\mathrm{p}=0.096$ as shown in tableII.

Table-I: Demographics $(n=139)$.

\begin{tabular}{ccc}
\hline Age(years) & Mean \pm SD & Range \\
\hline $\begin{array}{ccc}\text { Duration of symptoms } \\
\text { (years) }\end{array}$ & $2.1 \pm 0.27$ & $\mathbf{2 0 - 6 0}$ \\
T-score & & $1-4$ \\
Category & $-2.7 \pm 0.9$ & $1-3$ \\
Male & Frequency & $\%$ \\
Female & 75 & $53.95 \%$ \\
\hline
\end{tabular}

\section{Osteoporosis}

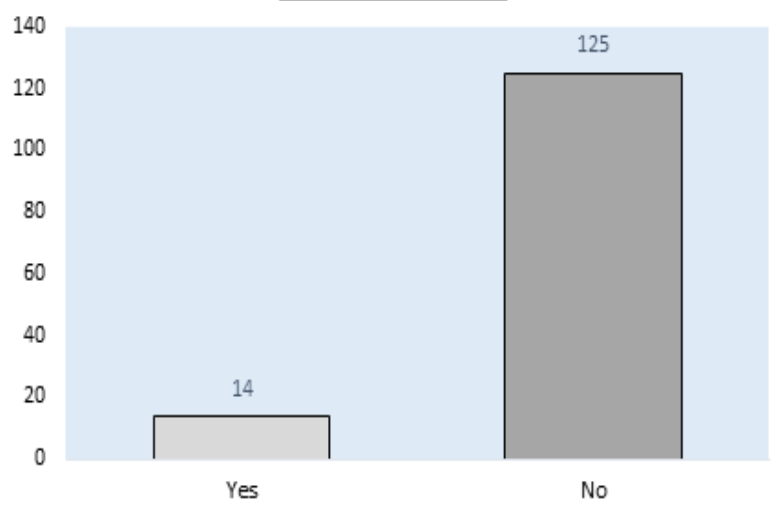

Table-II: Osteoporosis and study variables $(n=139)$.

\begin{tabular}{|c|c|c|c|c|}
\hline \multirow[t]{2}{*}{ Variables } & & \multicolumn{2}{|l|}{ Osteoporosis } & \multirow[t]{2}{*}{ p-value } \\
\hline & & Yes & No & \\
\hline \multirow[t]{2}{*}{ Gender } & Male & $05(6.67 \%)$ & $70(96.43 \%)$ & \\
\hline & Female & $09(14.06 \%)$ & $55(90.62 \%)$ & 0.148 \\
\hline \multirow[t]{2}{*}{ Age } & $20-39$ years & $7(9.58 \%)$ & $66(93.75 \%)$ & \\
\hline & $40-60$ years & $7(10.60 \%)$ & $59(92.85 \%)$ & 0.842 \\
\hline \multirow{2}{*}{$\begin{array}{l}\text { Duration } \\
\text { of } \\
\text { symptoms }\end{array}$} & Up to 2 years & $4(5.80 \%)$ & $65(93.75 \%)$ & \\
\hline & $\begin{array}{c}\text { More than } 2 \\
\text { years }\end{array}$ & $10(14.28 \%)$ & $60(92.85 \%)$ & 0.096 \\
\hline
\end{tabular}

\section{DISCUSSION}

Osteoporosis is a highly morbid entity and can further affect the cases suffering from peptic ulcer disease. The data has shown the increased prevalence in such cases. Underlying mechanisms are complex and prompt intervention can prevent a foreseen fracture in such cases that can add to even more social, psychological and financial stress on these cases ${ }^{[10]}$.

In the present study osteoporosis in cases of PUD was observed in $14(10.07 \%)$ out of 139 cases. These results were comparable with the findings of the studies done in the past where both higher and lower parentages of these cases were seen. According to a study done by Khalid et al., osteoporosis was noted in $6.67 \%$ of their 60 cases suffering from PUD. They found a significantly higher number in the female population, affecting $9.38 \%$ cases compared to $3.57 \%$ males. This was similar to the present study where females were more commonly affected than males, i.e., $14.06 \%$ vs $6.67 \%{ }^{[11]}$. In another study done by Yoon PH et al, where they assessed a long term follow up on cases with PUD with a mean follow up time was 12 years, and they found that there is an increased tendency of osteoporosis in such cases and they further described that the incidence was $11.1 \%(21 / 189)$ in males and $29.9 \%(56 / 187)$ in females in their PUD group. This was also supported by the result of the present study where osteoporosis was seen in $05(6.67 \%)$ males vs 09 (14.06\%) females in their respective groups with $p=0.148$, but overall percentages were higher in their study, 
and this might be due to the fact that they followed the cases for a longer period of time where chances of osteoporosis could have been higher as compared to our study ${ }^{[12]}$. Overall, the ratio of males and females was near to $1: 1$ with a slight predominance of males presenting with PUD, and this can be associated with smoking habits which were beyond the scope of this study.

Sawicki et al described a relatively lower percentages and it was seen in their study that osteoporosis was observed in about 5\%. They also had a comparative control group and found that the risk of developing the disease was double than that of the control group ${ }^{[13]}$.

Wu Ch et al., described that incidence was higher in cases with PUD especially those, who had positive $\mathrm{H}$ pylori and female gender. A higher number of females having this entity can be explained by the factor that females are more susceptible due to various hormonal factors, i.e. during menopause and at higher ages. The risk of osteoporosis is already high in females as compared to males ${ }^{[14]}$. Furthermore, this was also indirectly incorporated in the present study where the data has shown significant association of longer the duration, and higher were the chances of developing osteoporosis i.e. those having disease $>2$ years. Though no such cut off values was used in previous studies.

In a Japanese study, there was a significant association found between osteoporosis and peptic ulcer disease caused by $\mathrm{H}$ Pylori infection. In their study, on multivariate analysis, odd ratios were observed for age (OR 1.13; 95\%CI 1.07-1.20), being female (OR 4.77; 95\%CI 1.78-12.77), BMI (OR 0.79 ; 95\%CI 0.68-0.92), H. pylori (OR 5.33; 95\%CI $1.73-$ 16.42), and PUD (OR 4.98; 95\%CI 1.51-16.45) ${ }^{[15]}$. But no significant difference was observed in the present study in terms of age groups with $\mathrm{p}=0.842$.

In another study done by Shih $\mathrm{H}$ et al they found that the risk of osteoporosis was higher in cases suffering from $\mathrm{H}$ pylori disease. They descried that higher in the early H. pylori treatment cohort (hazard ratio $[\mathrm{HR}]=1.52,95 \%$ confidence interval $[\mathrm{CI}]=1.23-1.89$ ) and late $\mathrm{H}$. pylori treatment cohort $(\mathrm{HR}=1.69,95 \% \mathrm{CI}=1.39-2.05)$, compared with the risk in the control cohort. This infection is highly associated with an increased degree of peptic ulcer formation and hence the association with $\mathrm{H}$ pylori reveal early steps for detection and then in eradication of this entity ${ }^{[16]}$.

In another study by Nassar et revealed that this incidence was higher in cases that had longer duration of the disease; though they didn't use the cut off values used in present study and they further described that the incidence was significantly higher in cases that used PPIs for longer period of time and also had a higher risk of fractures with incidence of $22.04 \%$ (95\% CI, 16.10-27.97) in PPI users and $15.57 \%$ (95\% CI, 12.28-18.86) in controls ${ }^{[17]}$. Osteoporosis is becoming prevalent in Pakistan ${ }^{[18-19]}$. Therefore, early diagnosis of the disease is important inorder to prevent complications associated with it.

\section{CONCLUSION}

Osteoporosis is not uncommon in cases with Peptic ulcer disease, and there is no significant association with any of the confounders of this study.

ACKNOWLEDGMENT: We acknowledge all the colleagues for their effort in helping data collection. CONFLICT OF INTEREST: All authors declare no conflict of interest.

GRANT SUPPORT \& FINANCIAL DISCLOSURE: None.

\section{REFERENCES:}

1. Narayanan P. Peptic ulcer disease and Helicobacter pylori infection. Missouri Medicine. 2018;115(3):219224. PMCID: PMC6140150

2. Lanas A, Chan FKL. Peptic ulcer disease. Lancet. 2017;390(10094):613-624. Doi: 10.1016/S01406736(16)32404-7.

3. Azhari H, Underwood F, King J, Coward S, Shah S, Ng $\mathrm{S}$, et al. A 36 The global incidence of peptic ulcer disease and its complications at the turn of the 21 st century: a systematic review. Journal of Canadian Association of Gastroenterology. 2018;(suppl_2):61-62. Doi: 10.1093/ jcag/gwy009.036

4. Strand DS, Kim D, Peura DA. 25 years of proton pump inhibitors: A comprehensive review. Gut Liver. 2017;11(1):27-37. Doi: 10.5009/gnl15502

5. Johnston CB, Dagar M. Osteoporosis in Older Adults. Medical Clinics of North America. 2020;104 (5):873884. Doi: 10.1016/j.mcna.2020.06.004.

6. Jakobsen A, Laurberg P, Vestergaard P, Andersen S. Clinical risk factors for osteoporosis are common among elderly people in Nuuk, Greenland. International Journal of Circumpolar Health. 2013;72(8):1-Doi: 10.3402/ijch.v72i0.19596.

7. Yang M, He M, Zhao M, Zou B, Liu J, Luo LM, et al. Proton pump inhibitors for preventing non-steroidal anti-inflammatory drug induced gastrointestinal toxicity: a systematic review. Current Medical Research and Opinion. 2017;33(6):973-980. Doi: 10.1080/03007995.2017.1281110.

8. Chey WD, Leontiadis GI, Howden CW, Moss SF. ACG clinical guideline: treatment of Helicobacter pylori infection. American Journal of Gastroenterology. 2017;112(2):212-239. Doi: 10.1038/ajg.2016.563.

9. Fardous S, Rashid Z. Osteoporosis in peptic ulcer disease. Indo American Journal of Pharmaceutical Sciences. 2020;07(04):576-579.

10. Baig M, Tariq S, Tariq S. Homocysteine and leptin in the pathogenesis of osteoporosis-evidences, conflicts and expectations. Advances in Osteoporosis. 2015. https://www.intechopen.com/chapters/48218

11. Khalid Z, Aslam S, Khuwaja MM. Osteoporosis in cases of peptic ulcer disease. World Journal of Pharmaceutical and Medical Research. 2010;5(6):318-320. 
12. Yoon $\mathrm{PH}$, An SJ, Jeong SH, Yang YJ, Hong YP. Association between peptic ulcer disease and osteoporosis: the population-based longitudinal cohort study in Korea. International Journal of Environmental Research and Public Health. 2019;16(15):2777. Doi: 10.3390/ijerph1615277

13. Sawicki A, Regula A, Godwod K, Debinski A. Peptic ulcer disease and calcium intake as risk factors of osteoporosis in women. Osteoporosis International. 2003;14(12):983-986. Doi: 10.1007/s00198-003-14593.

14. Wu CH, Tung YC, Chai CY, Lu YY, Su YF, Tsai TH, et al. Increased risk of osteoporosis in patients with peptic ulcer disease. A nationwide population-based study. Medicine (Baltimore). 2016;95(16):e3309. Doi: 10.1097/md.0000000000003309

15. Asaoka D, Nagahara A, Shimada y, Mastsumoto $\mathrm{K}$, Ueyama H, Matsumoto K, et al. Risk factors for osteoporosis in Japan: is it associated with Helicobacter Pylori? Therapeutic Clinical Risk Management. 2015;11:381-391. Doi: 10.2147/TCRM.S80647

16. Shih HM, Hsu TY, Chen CY, Lin CL, Kao CH, Chen $\mathrm{CH}$, et al. Analysis of patients with Helicobacter pylori infection and the subsequent risk of developing osteoporosis after eradication therapy: a nationwide population-based cohort Study. PLoS ONE. 2016;11(9):e0162645. Doi.10.1371/journal. pone. 0162645

17. Nassar Y, Richter S. Proton-pump inhibitor use and fracture risk: an updated systematic review and metaanalysis. Journal of Bone Metabolism. 2018; 25:141151. Doi: $10.11005 / \mathrm{jbm} .2018 .25 .3 .141$.

18. Tariq S, Tariq S, Lone KP. Interplay of vitamin $D$, vitamin B12, homocysteine and bone mineral density in postmenopausal females. Health Care for Women International. 2018;39(12):1340-1349. Doi.org/10.108 0/07399332.2018.1444042

19. Tariq S, Baig M, Tariq S, Shahzad M. Association of serum leptin with bone mineral density in postmenopausal osteoporotic females. Gynecological Endocrinology. 2017;33(4):287-291. Doi:10.1080/095 13590.2016.1261103.

\section{Author's Contribution:}

Amber Amin: Designed and conducted the research, analyzed the data and prepared the manuscript.

Qaisar Farooq: Collected the data, carried out the literature search, helped in analyzing the data and prepared the manuscript.

Rizwan Jameel: Carried out the literature search, prepared and revised the manuscript.
Submitted for Publication:18-01-2021 Accepted after revision: 13-09-2021 